\title{
A Pandemia Covid-19 e o Estado de Emergência em Portugal: Breves Considerações Sobre Políticas Públicas
}

\author{
Leandro Berenguer*
}

* NOVA School of Law - Universidade Nova de Lisboa, Portugal; 1mcberenguer@gmail.com

\begin{abstract}
Resumo
A pandemia COVID-19 impeliu a que os Estados adotassem medidas excecionais por forma a conter os seus índices de propagação e, por conseguinte, mitigar os seus efeitos. Em Portugal, surgiu a necessidade de recorrer à figura do estado de emergência, tendo sido utilizada pela primeira vez desde a fundação da III República. Por forma a responder a uma situação de calamidade pública, recorreu-se à suspensão, ainda que parcial, de direitos, liberdades e garantias fundamentais, adotando medidas com reflexos nos mais variados domínios da sociedade civil. Tendo como ponto de partida o contexto securitário de um Estado, este artigo pretende analisar as declarações do estado de emergência em Portugal à luz do quadro teórico de políticas públicas, refletindo sobre o processo de implementação do estado de emergência. Para tal, são apostas em confrontação as abordagens top-down e bottom-up como principais teorias de implementação de políticas públicas na análise a um contexto político inédito em Portugal.
\end{abstract}

Palavras-chave: bottom-up; estado de emergência; pandemia; políticas públicas; segurança; top-down 


\begin{abstract}
The COVID-19 pandemic prompted States to adopt exceptional measures to contain their spreads rates and therefore mitigate their effects. In Portugal there was a need to resort to the figure of the state of emergency, being used for the first time since the foundation of the third Republic. To respond to a situation of public calamity, the suspension, albeit partial, of fundamental rights, freedoms and guarantees was used, adopting measures with repercussions in the most varied areas of civil society. Based on the security context of a State, this article intends to analyse the declarations of the state of emergency in Portugal in the light of the theoretical framework of public policies, reflecting on the process of implementing the state of emergency. To this end, the top-down and bottom-up approaches are placed in confrontation as the main theories of public policies implementation in the analysis of the unprecedented political context in Portugal.
\end{abstract}

Keywords: bottom-up; pandemic; public policies; security; state of emergency; top-down

\title{
1. Introdução
}

A conjuntura securitária atual é amplamente influenciada por eventos de natureza multidimensional comportando em si a capacidade de projetar a adoção de um conjunto de políticas excecionais orientadas para a resolução de tais acontecimentos. Neste sentido, tendemos não raras vezes a encarar esse conjunto de eventos enquanto crises respeitantes a um domínio em particular.

Na visão de Robert Darling e Stephen Young (2018, p. 120), a catalogação de um determinado fenómeno enquanto crise constitui-se como uma construção holística a qual, invariavelmente, apresenta reflexos em diferentes domínios, pugnando por uma conjugação de respostas de diferentes entidades. Assim, as crises potenciam a formação de políticas públicas, nas quais diferentes áreas do conhecimento convergem para uma atuação integrada e direcionada à mitigação e resolução da mesma.

Não obstante a natureza primária de uma determinada crise, o contexto securitário dos Estados é influenciado através dos reflexos naturais nos seus domínios, bem como exerce uma influência nas políticas tendentes à resolução do problema. Nesta conjugação de realidades, o domínio das políticas públicas afirma-se como o campo no qual "[...] necessidades, poderes, vontades, interesses individuais e coletivos se permeiam e fundam em realidades em mudança [...]” (Sarmento, 2012, p. 8).

Assim, afirma-se uma relação simbiótica entre os contextos da política e da segurança, enquanto dimensões sociais que se conjugam tendo em vista os desafios à segurança do Estado (Correia, 2012, p. 25). Sob a égide do ponto de vista securitário, o presente artigo debruça-se sobre as declarações do estado de emergência em Portugal, por força da pandemia COVID-19, tecendo breves considerações sobre os processos de implementação de políticas públicas. Presentemente, numa perspetiva de governança da segurança, exige-se às políticas públicas uma capacidade de con- 
gregar diferentes áreas de conhecimento, conjugando esforços para a implementação de soluções do problema que se constitui como o centro nevrálgico da política.

Todavia, surgem ocasiões nas quais o órgão que conduz o processo de formação de políticas públicas avoca a si a responsabilidade de definição e implementação das mesmas, designando as entidades cuja responsabilidade se centra na mera execução das medidas delineadas. Nesta linha de pensamento, sugere-se uma dupla perspetiva de implementação de políticas públicas, através das abordagens de top-down e bottom-up, nas quais a diversidade de atores e o método de implementação de uma política pública auxiliam na definição e distinção de ambos os métodos.

\section{As Abordagens de Implementação de Políticas Públicas}

Enquanto instrumento capital da atividade governativa, as políticas públicas surgem inseridas numa ótica de resposta a um conjunto de necessidades e exigências que visam representar uma realidade carenciada de uma intervenção tendente à satisfação dessas necessidades e exigências. A este propósito, David Easton (1957, p. 387) destaca que estes elementos, denominados de inputs, providenciam a informação ao sistema, enquanto se constituem como os catalisadores de todo o restante processo de produção de políticas públicas. O enquadramento de uma política no domínio público transporta-a para uma área de intervenção estatal, sendo comumente atribuída a um ato proveniente de um nível de autoridade pública, consubstanciando-se numa ação orientada para a resolução de um problema público (Birkland, 2011, p. 9).

Por sua vez, a definição de um problema, a priorização da ação política e a tomada de decisão confluem no ciclo de produção de políticas que, através da convergência da atuação de um conjunto de atores, estabelece um conjunto de fases e dinâmicas (Pasquino, 2010, pp. 300-301). Tendo cada fase do processo de formação a sua relevância nos outputs da política a produzir, a etapa da implementação surge, não só como o conjunto de processos que se destina à introdução de uma mudança no ambiente envolvente, bem como presta um importante feedback a todo o processo que precedeu à execução da política (Hill, 2005, p. 8).

Numa conjuntura securitária cada vez mais incerta, iminentemente pelos desafios complexos e difusos que impendem sobre os estados, as políticas públicas não podem dispensar os contributos provenientes de uma multitude de áreas de conhecimento, conjugando desse modo um leque variado de instrumentos para fazer face aos desafios securitários. Neste sentido, a capacidade de resposta por parte das políticas públicas de segurança assenta na mobilização das “[...] instituições de segurança de regulação social, nas quais se insere inevitavelmente a Polícia, bem como outros parceiros, nomeadamente coletividades locais, associações e empresas de índole pública ou privada" (Carvalho, 2018, p. 105).

Desta forma, e focando na raiz da nossa análise, os processos de implementação de uma política pública tendem a refletir a atuação de diferentes atores através de duas grandes teorias: a abordagem top-down e a abordagem bottom-up. Através da introdução de uma mudança no ambiente de atuação da política, os dois métodos em 
confrontação consubstanciam-se em dois pontos de vista respeitantes ao papel dos distintos atores políticos e às principais características de aplicação de uma política pública.

O método top-down de execução de uma política pública pauta-se por dois grandes eixos, a centralidade e a verticalidade. A centralidade inerente a este método pressupõe que o curso normal do processo seja tendencialmente executado por um só autor, assentando no pressuposto de que o processo de implementação é impulsionado por uma decisão proveniente do órgão executivo do Estado, o Governo (Pülz e Treib, 2007, p. 90). Neste seguimento, prosseguem os autores, esta tipologia de abordagens consiste numa burocratização do processo de aplicação da política, sendo as leis e regulamentos os instrumentos que, por excelência, definem a implementação top-down.

No que diz respeito à verticalidade, esta teoria representa uma forma de execução do topo para a base, incumbindo aos últimos aplicar os objetivos e instrumentos definidos pelos primeiros. A definição clara dos objetivos a atingir, bem como dos instrumentos à disposição para a prossecução dos objetivos traçados, constituem-se como pilares deste tipo de abordagem (Birkland, 2011, p. 265).

A centralidade e a verticalidade inerentes aos processos top-down permitem uma execução de políticas de forma hierarquizada, na qual os decisores políticos exercem um controlo eficaz da sua implementação, tendo em vista o cumprimento dos objetivos delineados. Consequentemente, torna-se inequívoco que o decisor político se assume como o ator central nesta etapa, incumbindo-lhe não só a definição dos objetivos da política, como também a sua aplicação através de hierarquias sólidas que possibilitam a atribuição de responsabilidades referentes aos resultados obtidos.

Todavia, e perspetivando o ciclo de produção de políticas públicas enquanto campo de atuação de um leque alargado de atores, o método top-down revela determinadas lacunas. Na ótica de Lucie Cerna (2013, p. 18), esta abordagem relega para um segundo plano de considerações o papel de entidades cuja maior proximidade com o foco da política pública auxilia numa implementação com maior grau de eficácia. Na mesma linha de pensamento, Gianfranco Pasquino (2010, p. 303) contempla que este tipo de métodos é aplicado em políticas nas quais “[...] os decisores políticos tenham investido autoridade e prestígio". Assim, a centralidade dos processos de implementação num só ator pode potenciar a formação de diversos enviesamentos a uma compreensão holística do problema-base à política pública, bem como na avaliação dos resultados obtidos com a execução da política.

A abordagem bottom-up surge como o reverso da medalha do método top-down, sendo ambas as formas de implementação antagónicas. No método bottom-up, assinalam-se como principais características a descentralização da execução de uma política e os movimentos de verticalidade e horizontalidade dos atores envolvidos. Numa primeira nota, e ao contrário de um processo de execução política inteiramente controlado pelos decisores políticos, a abordagem bottom-up contempla um processo de implementação através do estabelecimento de uma rede interligada de 
atores variados, tendo em linha de conta múltiplas vertentes de abordagem ao ambiente de decisão política (Birkland, 2011, p. 268).

O nível decisório respeitante aos elementos essenciais do processo de implementação de uma política pública não se encontra concentrado num só ator. A descentralização permite que entidades, de áreas distintas, confluam num único ambiente de decisão, contribuindo para a execução da política pública. Para Pasquino (2010, p. 304), os street level bureaucrats, principais atores deste modelo de implementação, detêm "[...] os conhecimentos e poder suficientes para adaptar a política pública às características do seu público de referência [...]”. Porém, note-se que as sinergias criadas entre diferentes atores na base potenciam um processo de redefinição de objetivos e instrumentos da política pública, transmitindo-os até ao topo. Nesta senda, assiste-se a uma simbiose entre os movimentos de horizontalidade e verticalidade (Pülz e Treib, 2007, p. 93), na qual os primeiros exercem uma natural influência nos resultados dos últimos.

Além de possibilitar que as políticas públicas surjam como uma compreensão integral do problema, o método de implementação bottom-up tem em linha de conta “[...] os objetivos, estratégias e atividades dos atores responsáveis pela implementação [...]" (Cerna, 2013, p. 18), atribuindo-lhes um papel ativo na definição das formas de execução da política, ao invés da mera aplicação. Contudo, a forte descentralização que caracteriza este tipo de abordagens implica a dificuldade de exercer um controlo eficaz sobre as formas de aplicação da política, obstando à correta atribuição de responsabilidades pelas lacunas na execução da política.

Num contexto multidimensional de áreas alvo de intervenção de políticas públicas, as suas abordagens de implementação variam entre os modelos top-down e bottom-up, sendo que a escolha flutua de acordo com as características do problema alvo da política, dos objetivos delineados para a aplicação da mesma e ainda do contexto envolvente ao seu processo de definição e execução.

\section{O Decreto do Estado de Emergência em Portugal}

A figura do estado de emergência em Portugal encontra-se positivada no catálogo dos estados de exceção com previsão constitucional ${ }^{[1]}$, surgindo a par da figura de estado de sítio, ressalvadas as naturais diferenças. Embora previstas na Constituição da República Portuguesa e devidamente densificadas na previsão infraconstitucional ${ }^{[2]}$, apenas em 2020 surgiu a imperiosa necessidade em Portugal se proceder à declaração do estado de emergência. Numa era marcada por intensos processos de globalização, a criação de fluxos de pessoas e bens à escala mundial apresenta a capa-

1. A Constituição da República Portuguesa contempla no seu artigo 19. a possibilidade da suspensão do exercício de direitos, estatuindo para tal as figuras do estado de sítio e do estado de emergência. Para uma melhor compreensão vide Decreto de Aprovação da Constituição, de 10 de abril de 1976. Diário da República, 1. a Série, n. ${ }^{\circ} 86,738-775$ (aprova a Constituição da República Portuguesa).

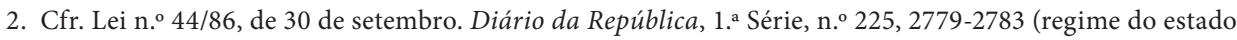
de sítio e do estado de emergência). 
cidade de ampliar um determinado fenómeno de aparente dimensão local, transformando-o num assunto de agenda global.

Nesta senda, a doença COVID-19 tornou-se numa pandemia após a qualificação pela Organização Mundial de Saúde. A assunção de um problema de saúde pública, com expressão global e elevados índices de propagação, apresentou reflexos inegáveis em diversos domínios societais, afetando inexoravelmente áreas como a saúde, a economia e a segurança nacional.

De forma transversal à comunidade civil, a declaração do estado de emergência em Portugal revelou-se capaz de permitir a adoção de um conjunto de medidas atinentes à prevenção da rápida propagação da doença. Assim, sublinhe-se que a adoção deste estado de exceção dá-se em dois momentos distintos, nomeadamente, na fase inicial em que se registaram os primeiros casos de COVID-19 em território nacional e, numa segunda fase, na qual se assiste a uma evolução vertiginosa dos diferentes indicadores relativos à propagação da doença.

A previsão do estado de emergência no ordenamento jurídico nacional contempla a suspensão parcial de direitos, liberdades e garantias, bem como os limites impostos à restrição do exercício de direitos constitucionalmente consagrados. Neste sentido, as diversas declarações do estado de emergência ${ }^{[3]}$, efetivadas por recurso à figura do Decreto do Presidente da República ${ }^{[4]}$, observam essencialmente direitos, liberdades e garantias suspensos e o respetivo escopo da suspensão, bem como o conjunto de direitos, liberdades e garantias insuscetíveis de violação normativa.

A este propósito, as declarações do estado de emergência refletiram dois aspetos importantes que auxiliam na compreensão das dinâmicas inerentes ao recurso a este instrumento jurídico. Primeiramente, a estatuição do estado de emergência e das sucessivas renovações assentou na evolução da situação epidemiológica, na ineficácia de outros instrumentos jurídicos ${ }^{[5]} \mathrm{e}$ ainda decorrente dos eventos calendarizados e da necessidade de proceder à limitação da sua realização. Num segundo aspeto as-

3. Cf. Decreto do Presidente da República n. ${ }^{\circ} 14-\mathrm{A} / 2020$, de 18 de março. Diário da República, $1 .^{\mathrm{a}}$ Série, n. ${ }^{\circ}$ 55, 13-(2)-13(4). (declara o estado de emergência, com fundamento na verificação de uma situação de calamidade pública); Decreto do Presidente da República n. ${ }^{\circ}$ 17-A/2020, de 2 de abril. Diário da República, $1 .{ }^{\text {a }}$ Série, n. ${ }^{\circ}$ 66, 31-(2)-31(5). (renova a declaração do estado de emergência, com fundamento na verificação de uma situação de calamidade pública); Decreto do Presidente da República n. ${ }^{\circ} 20-\mathrm{A} / 2020$, de 17 de abril. Diário da República, 1. ${ }^{a}$ Série, n. ${ }^{\circ}$ 76, 7-(2)-7(5). (procede à segunda renovação da declaração do estado de emergência, com fundamento na verificação de uma situação de calamidade pública); Decreto do Presi-

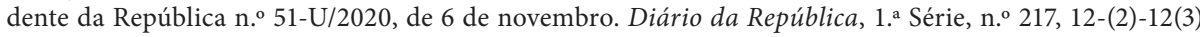
(declara o estado de emergência, com fundamento na verificação de uma situação de calamidade pública).

4. A declaração de qualquer um dos estados de exceção encontra-se na esfera de competências do Presidente da República, depois de realizada a audição do Governo e de obtida a autorização da Assembleia da República, devendo adotar a forma de decreto do Presidente da República. Para uma melhor compreensão vide

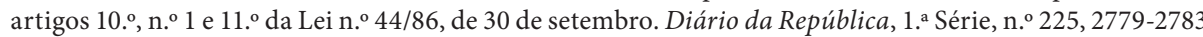
(regime do estado de sítio e do estado de emergência).

5. No âmbito da Lei de Bases de Proteção Civil, já havia sido declarada a situação de alerta em todo o território nacional, precedendo deste modo à declaração do estado de emergência. Para um melhor entendimento dos moldes inerentes à situação da alerta cfr. artigo $9 .^{\circ}$, n. ${ }^{\circ} 1$ da Lei n. ${ }^{\circ} 27 / 2006$, de 3 de julho. Diário da República, 1. ${ }^{a}$ Série, n. ${ }^{\circ}$ 126, 4696-4706 (aprova a Lei de Bases de Proteção Civil). 
sistiu-se à necessidade de se proceder a um ponderado equilíbrio entre as restrições conducentes à propagação da doença e o desenvolvimento da economia nacional, sublinhando-se movimentos de alargamento e retraimento dos direitos, liberdades e garantias alvos de suspensão parcial.

Relativamente às medidas pertencentes à implementação da suspensão dos direitos, liberdades e garantias, os decretos de execução do estado de emergência estatuem distintos eixos de execução das suspensões previstas. Na primeira fase da pandemia e no que diz respeito à suspensão da liberdade de circulação em território nacional, as medidas adotadas estruturavam-se em três grandes eixos: medidas de confinamento obrigatório (para os doentes por COVID-19 e os infetados com SARS-Cov2 ${ }^{[6]}$ ); as medidas respeitantes à implementação de um dever especial de proteção ${ }^{[7]}$; e as medidas destinadas à aplicação do dever geral de recolhimento domiciliário ${ }^{[8]}$. Na mesma ótica, estabeleceram-se ainda medidas de limitação do exercício da atividade económica e de restrição e encerramento de espaços públicos e privados. Por sua vez, com a segunda vaga da pandemia e nova declaração do estado de emergência, além da continuação de limitação da liberdade de circulação, as novas medidas consubstanciaram-se numa lógica de reforço da capacidade de prevenção e resposta à COVID-19 ${ }^{[9]}$.

Se por um lado a implementação das medidas delineadas apresentava reflexos nos domínios da saúde e da economia do país, por outro lado, a execução pugnava por uma reconfiguração do contexto securitário. Aquando do primeiro decreto de estado de emergência, a fiscalização das medidas pertencia, numa primeira fase, às forças de segurança, juntando-se posteriormente as polícias municipais, em complemento da ação das anteriores ${ }^{[10]}$. Os referidos decretos previam um conjunto de linhas orien-

6. As medidas de confinamento obrigatório visavam impedir qualquer deslocação dos doentes com COVID-19 e dos infetados com SARS-Cov2, bem como os cidadãos a quem estivesse determinada a vigilância ativa. O escopo da presente medida previa ainda a punição pelo crime de desobediência pela violação da estatuição prévia.

7. As medidas inseridas no catálogo do dever especial de proteção destinavam-se aos cidadãos maiores de 70 anos bem como aos imunodeprimidos e portadores de doenças crónicas, limitando o seu direito de circulação a um leque muito reduzido de cenários de circulação na via pública.

8. O dever geral de recolhimento domiciliário aplicava-se a todos os cidadãos que não figurassem nas outras duas categorias, pendendo sobre os mesmos um conjunto de exceções à suspensão do seu direito de livre circulação.

9. Sublinhe-se o preâmbulo do decreto de execução do estado de emergência ao assinalar a necessidade implementar medidas no âmbito "[...] da liberdade de deslocação, do controlo do estado de saúde das pessoas, da utilização de meios de prestação de cuidados de saúde do setor privado e social ou cooperativo e da convocação de recursos humanos para reforço da capacidade de rastreio". Sobre este assunto vide Decreto n 8/2020, de 8 de novembro. Diário da República, 1. Série, n 217-A, 2-8 (regulamenta a aplicação do estado de emergência decretado pelo Presidente da República).

10. Primeiramente, o Decreto n. ${ }^{\circ} 2-\mathrm{A} / 2020$ previa somente a ação de fiscalização das forças de segurança. Numa segunda fase, e decorrente das duas renovações do estado de emergência, ficou prevista as atribuições da polícia municipal em matéria de fiscalização. Sobre este assunto vide o artigo 32. ${ }^{\circ}$ do Decreto

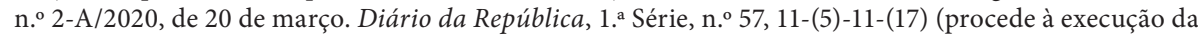
declaração do estado de emergência efetuada pelo Decreto do Presidente da República n. ${ }^{\circ} 14-\mathrm{A} / 2020$, de

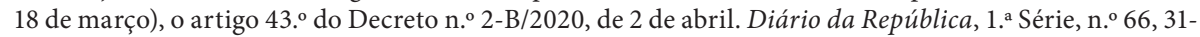


tadoras, procedendo à definição concreta das principais áreas de fiscalização ${ }^{[11]}$, bem como à aplicação de medidas de cariz sancionatório em casos específicos de violação das medidas ${ }^{[12]}$, assegurando deste modo a não arbitrariedade da restrição de direitos, liberdades e garantias por parte dos órgãos responsáveis pela etapa de implementação.

A declaração do estado de emergência revelou-se como uma política inédita e de exceção no panorama nacional, destinada à resolução de um problema de saúde pública de caráter internacional. Por sua vez, a formulação de medidas conducentes à implementação da suspensão de direitos, liberdades e garantias configurou-se como um processo de elevada responsabilidade política, enquanto conjugava áreas de intervenção como a saúde, a economia, a segurança, a justiça e a educação.

Numa dimensão securitária, a instauração do estado de emergência representou não só a suspensão de direitos, liberdades e garantias, como também a reconfiguração da atividade das forças e serviços de segurança do Estado, por forma a providenciar uma resposta cabal à execução das medidas atinentes à prossecução da referida suspensão. À luz da doutrina existente e do ponto de vista securitário, afigura-se adequado afirmar que os processos de declaração do estado de emergência e a consequente formulação e implementação das medidas de execução dos mesmos seguiram, de forma bipartida, uma abordagem híbrida entre os modelos top-down e bottom-up.

No que concerne à primeira declaração do estado de emergência e sucessivas renovações considere-se o modelo de implementação top-down como aquele que guiou o processo de produção política. Assim, importa destacar a natureza estatutária das funções do Governo em matéria de regulamentação do decreto de um estado de exceção. Enquanto órgão responsável pela execução dos decretos presidenciais ${ }^{[13]}$, incumbe formalmente ao Governo a tarefa de executar a declaração dos estados de exceção previstos, delineando para tal as medidas adequadas às fundamentações das referidas declarações.

De seguida, assinala-se o peso das razões de natureza histórica para que o Governo português assumisse o controlo no processo da implementação. A notoriedade da opção política inspirou no Governo cuidados redobrados pelas medidas executórias a adotar. Neste âmbito, e embora tenham volvidos 46 anos da queda de um re-

(2)-31-(20). (regulamenta a prorrogação do estado de emergência decreto pelo Presidente da República) e o artigo $46 .^{\circ}$ do Decreto n. ${ }^{\circ}$-C/2020, de 17 de abril. Diário da República, $1 .^{\text {a Série, n.o } 76,7-(9)-7-(28)}$ (regulamenta a prorrogação do estado de emergência decreto pelo Presidente da República).

11. As principais áreas de fiscalização centravam-se no encerramento dos estabelecimentos e atividades obrigadas à não laboração, no aconselhamento da não concentração de pessoas na via pública e ainda na recomendação de todos os cidadãos para o cumprimento do dever geral de recolhimento domiciliário.

12. Neste domínio, o quadro sancionatório apenas contemplava a punição pelo crime de desobediência em respeito à violação do disposto para o encerramento das atividades económicas, bem como à violação da obrigatoriedade de confinamento.

13. Vide artigo $17 .^{\circ}$ da Lei n. ${ }^{\circ} 44 / 86$, de 30 de setembro. Diário da República, $1 .^{\text {a }}$ Série, n. $.^{\circ} 225,2779-2783$ (regime do estado de sítio e do estado de emergência). 
gime ditatorial em Portugal, note-se que o panorama das restrições de direitos, liberdades e garantias constatadas nesse período permanece na memória política atual, levando a decisões políticas pautadas pela parcimónia, característica essa também vertida nos diversos períodos de vigência do estado de emergência.

Nesta exata medida surgiu a necessidade do executivo delinear um catálogo extenso de limitações, mas também das exceções à suspensão dos direitos, liberdades e garantias, garantindo que critérios de discricionariedade não se constituíssem como as principais orientações do sentido de responsabilidade que impende sobre a declaração de um estado de emergência e, por conseguinte, das entidades responsáveis pela execução e fiscalização.

A condução do processo político recaiu sobre a esfera de responsabilidades do Governo, incumbindo-lhe a formulação das medidas a implementar bem como a designação das entidades responsáveis e das respetivas atribuições de execução e fiscalização. Através de um rigoroso processo de definição taxativa do escopo da suspensão de direitos e dos limites da execução e fiscalização, o Governo procurou assegurar o controlo da implementação das medidas, prosseguindo para tal dois desideratos nucleares inerentes a um modelo de implementação top-down.

Em primeiro lugar, as opções políticas visaram assegurar um controlo da eficácia da implementação das medidas delineadas, almejando evitar que a doença COVID-19 atingisse taxas de propagação semelhantes às de outros países e garantindo que a sociedade civil se encontrasse munida de condições para desenvolver o seu quotidiano a par de um problema de saúde pública com expressão internacional. Em segundo lugar, a hierarquização das medidas adotadas propôs-se a estruturar os níveis de execução política, bem como os níveis de responsabilização inerentes ao papel dos diferentes atores. Desta forma, a adoção da abordagem top-down permitiu ao governo delinear as medidas de execução da primeira fase do estado de emergência, recorrendo a processos de verticalidade para a implementação e consequente controlo da execução.

Por conseguinte, a declaração do estado de emergência, inserida num contexto de segunda vaga da pandemia COVID-19, procurou assentar os seus pilares em novos pressupostos, aliando a experiência dos dois primeiros trimestres de 2020 à realidade económica e sanitária nacional. Deste modo, e além da audiência aos especialistas em matéria de saúde, registou-se a receção por parte do Presidente da República de centrais sindicais bem como de confederações ligadas a setores económicos nevrálgicos do país, acentuando a necessidade de encontrar o correto equilíbrio entre a saúde pública e a economia do país ${ }^{[14]}$.

Respeitante ao contexto securitário, constata-se que a previsão da atividade das forças e serviços de segurança se efetuou nos moldes já anteriormente apresentados.

14. Nesta matéria atente-se aos diferentes encontros entre Presidente da República e representantes da saúde (SIC Notícias (2020). Marcelo faz ronda de reuniões com representantes da saúde para chegar a consenso) e também com os respetivos parceiros sociais nos diferentes setores (Público (2020). Marcelo vai ouvir parceiros sociais sobre estado de emergência). 
Todavia, ressalva-se que a vigência de um novo estado de emergência, embora de cariz preventivo e mais limitado, comporta em si uma cláusula aberta no que concerne à aplicação do regime sancionatório. Neste ponto, enquanto as sanções em vigor no primeiro estado de emergência reportavam-se a um conjunto restrito de violações das medidas previstas, o atual quadro sancionatório é aplicável a qualquer violação das medidas atualmente em vigor ${ }^{[15]}$.

Em face de um contexto pandémico volátil, consideramos que, não obstante a opção do Governo em definir os domínios de fiscalização e respetivo quadro sancionatório das medidas de execução do estado de emergência, tal processo de implementação se revelou de forma ambivalente, flutuando entre os modelos de top-down e bottom-up. Porém, ressalve-se a predominância de aplicação por via do método top-down na primeira fase do estado de emergência e suas renovações e, por conseguinte, uma maior influência dos pressupostos de bottom-up no decreto do segundo estado de emergência.

\section{Conclusão}

A vigência do estado de emergência em Portugal revelou-se inédita não só pela declaração deste estado de exceção, como também por se afigurar um problema de saúde pública de dimensão global. A doença COVID-19 rapidamente ganhou expressão internacional, tornando-se num problema pandémico e com níveis de propagação elevados. A par desta conjuntura, diversos Estados recorreram aos respetivos instrumentos jurídicos capacitados para lidar com as características da pandemia em curso, nomeadamente através da limitação do gozo de direitos, liberdades e garantias fundamentais.

Também Portugal percecionou a necessidade de recorrer ao domínio dos estados de exceção como forma de restringir o exercício de direitos, em prol da preservação da saúde pública. As declarações do estado de emergência em diferentes fases da pandemia, e as suas sucessivas renovações, consubstanciaram-se no instrumento jurídico capaz de fornecer um leque alargado de medidas para a resolução de uma calamidade pública, enquanto assegurava um grau de confiança jurídica ${ }^{[16]}$ no que à limitação de direitos e liberdades e garantias diz respeito.

As abordagens top-down e bottom-up configuram-se nos métodos que marcam a fase de implementação das políticas públicas, sendo sobre estes que tendencialmente assenta a concretização da referida etapa. O método top-down fundamenta o seu processo em critérios de centralidade de atuação e de verticalidade de execução, partindo do órgão governativo do Estado a principal incumbência de definição dos

15. Para uma melhor compreensão vide o artigo $12 .^{\circ}$, n. $^{\circ} 1, \mathrm{c}$ ) do Decreto n. ${ }^{\circ} 8 / 2020$, de 8 de novembro. Diário

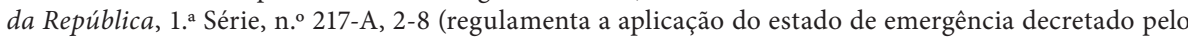
Presidente da República).

16. Vide o preâmbulo do Decreto do Presidente da República n. ${ }^{\circ} 14-\mathrm{A} / 2020$, de 18 de março. Diário da Re-

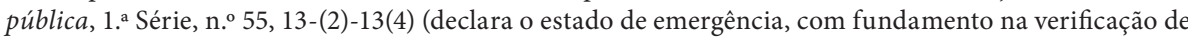
uma situação de calamidade pública). 
objetivos da política formulada, bem como dos instrumentos tendentes à execução, restando às entidades sob a égide do Estado a mera aplicação, numa lógica de implementação do topo para a base. A abordagem bottom-up privilegia a descentralização da decisão e confere uma simbiose entre a verticalidade e a horizontalidade de procedimentos, constatando-se uma influência nos processos de decisão política do topo, partindo dos conhecimentos e objetivos das entidades da base.

À luz do quadro teórico discutido no presente artigo, consideramos que o processo de implementação das duas fases do estado de emergência em Portugal efetivou-se com recurso a uma abordagem híbrida, entre os modelos top-down e bottom-up. Por um lado, a obrigação estatutária da regulamentação do estado de emergência e a sensibilidade de matérias relacionadas com a suspensão do exercício de direitos pugnou do Governo um processo de clara definição não só das limitações ao exercício de direitos, como também das limitações aos poderes de fiscalização e execução das referidas medidas. Por outro lado, a declaração do segundo estado de emergência veio refletir a imperiosa necessidade de conciliar as matérias de saúde pública, economia nacional e segurança, procurando um consenso entre a prevenção da propagação da doença, a atividade dos vários setores económicos e a fiscalização das medidas projetadas.

Assim, a implementação do estado de emergência, por se tratar de um processo político inédito em Portugal, instou ao Governo, numa primeira fase, a projeção e aplicação de medidas de execução por via de um modelo top-down. Porém, e quando confrontados com uma nova declaração do estado de emergência, tornou-se notório uma maior convergência de diferentes atores no processo de delineação das medidas e respetivos objetivos, revelando-se assim de maior predominância a abordagem bottom-up.

Data de receção: 18/09/2020

Data de aprovação: $17 / 11 / 2020$

\section{Referências}

\section{Obras Gerais}

Birkland, T. (2011). An introduction to the policy process: theories, concepts, and models of public policy making. New York: Routledge.

Carvalho, R. (2018). A influência das Políticas Públicas de Segurança no Reino Unido na Realidade Portuguesa. In Correia, E. P. (Coord.). Políticas Públicas de Segurança (pp. 99-143). Lisboa: Instituto Superior de Ciências Policiais e Segurança Interna.

Cerna, L. (2013). The Nature of Policy Change and Implementation: A Review of Different Theoretical Approaches. Paris: Organisation for Economic Co-operation and Development.

Correia, E. P. (2012). Política e Segurança: Teorias e Conjunturas da Atualidade. In Correia, E. P. e Duque, R. (Coord.). O Poder Político e a Segurança. Lisboa: Fonte da Palavra. 
Darling, R. e Young, S. (2018). Crisis leadership: A leader's new normal. In Engemann, K. (Ed.). The Routledge Companion to Risk, Crisis and Security in Business (pp. 120-143). New York: Routledge.

Easton, D. (1957). An Approach to the Analysis of Political Systems. World Politics, Vol. 9 (n. 3), pp. 383-400.

Hill, M. (2005). The Public Policy Process. (4. ${ }^{\text {e }}$ d.). Essex: Pearson Education Limited.

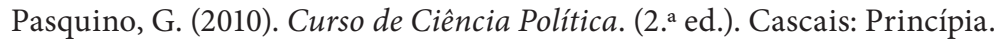

Pülz, H. e Treib, O. (2007). Implementing Public Policy. In Fischer, F., Miller, G. e Sidney, M. (Eds.). Handbook of Public Policy Analysis: Theory, Politics and Methods (pp. 89-107). Florida: CRC Press.

Sarmento, C. (2012). "Prefácio". In Correia, E. P. e Duque, R. (Coord.). O Poder Político e a Segurança (pp.7-9). Lisboa: Fonte da Palavra.

\section{Legislação}

Decreto no 2-A/2020, de 20 de março. Diário da República, 1. a Série, n 57, 11-(5)-11-(17) (procede à execução da declaração do estado de emergência efetuada pelo Decreto do Presidente da República no $14-\mathrm{A} / 2020$, de 18 de março).

Decreto n 2-B/2020, de 2 de abril. Diário da República, 1. ${ }^{\text {a Série, no }}$ 66, 31-(2)-31-(20) (regulamenta a prorrogação do estado de emergência decreto pelo Presidente da República).

Decreto no 2-C/2020, de 17 de abril. Diário da República, 1. a Série, nº 76, 7-(9)-7-(28) (regulamenta a prorrogação do estado de emergência decreto pelo Presidente da República).

Decreto $n^{\circ}$ 8/2020, de 8 de novembro. Diário da República, 1. ${ }^{a}$ Série, n $217-A, 2-8$ (regulamenta a aplicação do estado de emergência decretado pelo Presidente da República).

Decreto de Aprovação da Constituição no 86/1976, de 10 de abril. Diário da República, 1. ${ }^{a}$ Série, n. $86,737-775$ (aprova a Constituição da República Portuguesa).

Decreto do Presidente da República no ${ }^{\circ}$-A/2020, de 18 de março. Diário da República, 1 a $^{\mathrm{a}}$ Série, n. ${ }^{\circ}$ 55, 13-(2)-13(4) (declara o estado de emergência, com fundamento na verificação de uma situação de calamidade pública).

Decreto do Presidente da República no $17-A / 2020$, de 2 de abril. Diário da República, 1. ${ }^{\text {a Série, }}$ n. ${ }^{\circ} 66,31-(2)-31$ (5) (renova a declaração do estado de emergência, com fundamento na verificação de uma situação de calamidade pública).

Decreto do Presidente da República no 20-A/2020, de 17 de abril. Diário da República, 1. ${ }^{\text {a Sé- }}$ rie, n. ${ }^{\circ} 76,7-(2)-7(5)$ (procede à segunda renovação da declaração do estado de emergência, com fundamento na verificação de uma situação de calamidade pública).

Decreto do Presidente da República n..$^{\circ}$ 51-U/2020, de 6 de novembro. Diário da República, 1. ${ }^{a}$ Série, n. ${ }^{\circ} 217,12-(2)-12(3)$ (declara o estado de emergência, com fundamento na verificação de uma situação de calamidade pública).

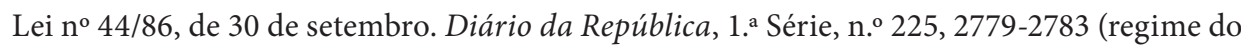
estado de sítio e do estado de emergência).

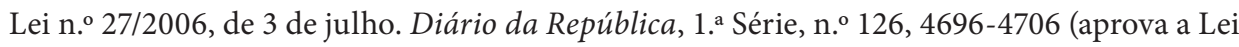
de Bases de Proteção Civil). 


\section{Imprensa}

SIC Notícias (2020). Marcelo faz ronda de reuniões com representantes da saúde para chegar a consenso, de 18 de outubro. Consultado em 12 de novembro de 2020, através de $<$ https://www.publico.pt/2020/11/02/politica/noticia/marcelo-vai-ouvir-parceirossociais-estado-emergencia-1937686>.

Público (2020). Marcelo vai ouvir parceiros sociais sobre estado de emergência, de 2 de novembro. Consultado em 12 de novembro de 2020, através <https://www.publico. pt/2020/11/02/politica/noticia/marcelo-vai-ouvir-parceiros-sociais-estadoemergencia-1937686>.

\section{Sobre o autor}

LEANDRO BERENGUER é doutorando em Direito e Segurança na NOVA School of Law da Universidade Nova de Lisboa, Mestre em Ciências Policiais pelo Instituto Superior de Ciências Policiais e Segurança Interna (ISCPSI), Oficial da Polícia de Segurança Pública e Investigador Associado do Observatório Político. [https://orcid.org/0000-0002-5604-4411]

\footnotetext{
About the author

LEANDRO BERENGUER is a PhD student in Law and Security in the NOVA School of Law, Master in Police Sciences by the Higher Institute of Police Sciences and Internal Security (ISCPSI), Public Security Police Officer and Associate Researcher at the Political Observatory. [https://orcid.org/0000-0002-5604-4411]
} 